\title{
Analysis of the occurrence of early life stress in adult psychiatric patients: a systematic review
}

\author{
Camila Maria Severi Martins, Sandra Marcia de Carvalho Tofoli, Cristiane Von Werne Baes and \\ Mario Juruena \\ University of Sao Paulo, Ribeirão Preto, SP, Brazil
}

\begin{abstract}
The purpose of the paper was to conduct a systematic review of early life stress and its association with psychiatric disorders in adulthood. The occurrence of early stress has lasting negative consequences on the individual, with psychopathology onset one of the most important consequences. The degree of early life stress is associated with the severity of psychiatric disorders and disability in adulthood. Methodology: We conducted a search of two databases (PubMed and SciELO), limited to the time span 1990-2010, using the following keywords: child abuse, maltreatment, early stress, and psychiatric disorders. Thirty-one papers were selected for this review. Results: We found that the subtypes of early life stress such as emotional and physical neglect and sexual, emotional, and physical abuse have associations with several psychiatric disorders, but the Borderline Personality Disorder and Mood Disorders are more associated with the categories listed. Conclusions: Exposure to adversities in childhood and adolescence is predictive of psychiatric disorders in adulthood. More studies are needed to understand the mechanisms by which early life stress is a risk factor for future psychopathology. Keywords: child abuse, maltreatment, early stress, psychiatric disorders.
\end{abstract}

Received 21 March 2011; received in revised form 7 May 2011; accepted 10 May 2011. Available on line 10 October 2011

\section{Introduction}

During childhood and adolescence, important brain structures are formed. The occurrence of traumatic events during this phase of development can cause enduring and negative neurobiological and neuroendocrine changes that remain throughout the life of victimized children. The effect of early life stress affects child development in the behavioral, emotional, social, cognitive, and physical domains (Anda et al., 2006; Bremne \& Vermetten, 2001; Cardoso, Santana, \& Ferriani, 2006; Juruena, 2007; Mello, Mello, Carpenter, $\&$ Price, 2003; Mello et al., 2009).

Childhood maltreatment is associated with a diverse range of psychiatric consequences. In children and

Camila Maria Severi Martins, Sandra Marcia de Carvalho Tofoli, and Cristiane Von Werne Baes, Research Fellow. PostGraduation in Mental Health. Department of Neuroscience and Behaviour. Faculty of Medicine Ribeirao Preto. University of Sao Paulo. Mario Juruena, Professor Doctor in Psychiatry. Head Stress and Affective Disorders Programme (SAD Programme). Department of Neurosciences and Behaviour. Faculty of Medicine Ribeirao Preto. University of Sao Paulo. Correspondence regarding this article should be directed to: Mario Juruena, Saúde Mental-USP, Av. Tenente Catão Roxo, 2650, Monte Alegre Campus Universitário, Ribeirão Preto, SP - Brazil 14051-140. E-mail: juruena@fmrp.usp.br adolescents, it increases the risk of behavioral problems, including internalizing (e.g., anxiety, depression) and externalizing (e.g., aggression, acting out) behavior (Abramovitch, Maia, \& Cheniaux, 2008; Mello et al., 2009). Moreover, its psychological consequences can acutely affect a child's mental health well into adulthood (Aded, Dalcin, Moraes, \& Cavalcanti, 2006; Brewerton, 2007).

The term early life stress refers to a variety of traumatic experiences that may occur during childhood and adolescence and the main types of found in the literature include:

A) Physical abuse of a child, defined as the intentional use of physical force against a child, resulting in or having a high likelihood of resulting in harm to the child's health, survival, development, or dignity. This includes hitting, beating, kicking, shaking, biting, strangling, scalding, burning, poisoning, and suffocating. Much of the physical violence against children at home is inflicted as a means of punishment.

B) Sexual abuse, defined as the involvement of a child in sexual activity that he or she does not fully comprehend, to which is unable to give informed consent, or for which is not mentally prepared or violates the laws or social taboos of society. Children can be sexually abused by adults, male and female, and other children who, by virtue 
of their age or stage of development, are in a position of responsibility, trust, or power over the victim.

C) Emotional and psychological abuse, involving isolated incidents and a pattern of failure over time on the part of a model or caregiver to provide a developmentally appropriate and supportive environment. Acts in this category may have a high probability of damaging the child's physical or mental health or physical, mental, spiritual, moral, or social development. Abuse of this type includes the restriction of movement, patterns of belittling, blaming, threatening, frightening, discriminating against or ridiculing. Other non-physical forms include rejection or hostile treatment.

D) Neglect, including isolated incidents and a pattern of failure over time on the part of a parent or other family member to provide for the development and well-being of the child when the parent is in a position to do so in one or more of the following areas: health, education, emotional development, nutrition, shelter, and safe living conditions (Butchart, 2006).

Furthermore, some studies suggest that exposure to some other stressors during childhood, such as the death of a parent or substitute, deprivation, maternal or paternal abandonment, separation or divorce, and parental psychiatric disorders, may also be associated with psychiatric disorders in adulthood (Zavaschi et al., 2002).

Currently, early life stress is a social problem that represents a substantial public health burden. Among some of the risk factors associated with early stress are excessive poverty, health problems, alcohol and drug use, low education level, and families who do not have a structured network of social support. Studies have shown that offenders often experienced difficult conditions including situations of abuse. Thus, these studies suggest the characteristic of intergenerational violence (i.e., a victimized child may tend to play a violent model throughout his course of life and become an adult perpetrator because the violence becomes a model for conflict resolution; Rosenberg, Drake, \& Mueser, 1996).

In contrast, protective factors are critical for mediating the effects of violence. Included in these factors is so-called resilience, defined as the ability to adapt to or overcome a difficulty previously considered a risk, beyond the possibility of constructing new ways of life and subjective processes. Other protective factors also include the child's dispositional attributes (e.g., activity, independence, positive social orientation, selfesteem, preferences), the family's characteristics (e.g., cohesion, affection, and an absence of discord and negligence), and the sources of support available to institutional or individual children and families (e.g., a child's relationship with colleagues and people outside the family, cultural support, and individual care provided by medical or psychological and religious institutions; Barnett, 1997; Brancalhone, Fogo, \& Williams, 2004; Webster-Stratton, 1997).

Because of the high incidence of early life stress in Brazil and worldwide, a better understanding of the mechanisms by which early life stress may trigger severe and disabling psychiatric disorders in adulthood is important. Thus, the objective of the present review was to systematically analyze the extant studies in the literature and discuss the association between early life stress and psychopathology.

\section{Methods}

We conducted a systematic review of articles indexed in PubMed and SciELO published between 1990 and 2010 in English and Portuguese. The search terms were the following: child abuse, maltreatment, early stress, and psychiatric disorders and their corresponding terms in Portuguese. We later refined the search through a systematic review of the articles' abstracts, excluding articles that did not examine predictive value.

The exclusion criteria were the following: review articles, animal studies, studies that evaluated the association between early life stress and psychiatric disorders in children/adolescents or the elderly, studies that evaluated the association between early life stress and other medical conditions, and articles in languages other than English or Portuguese.

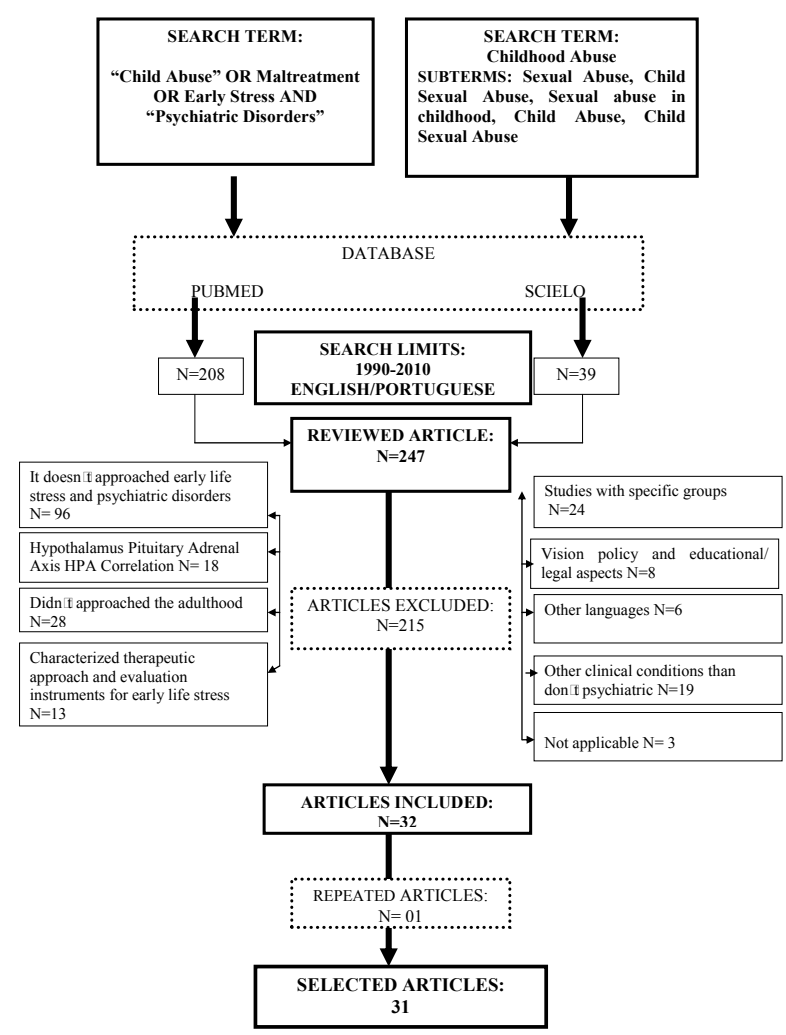

Figure 1. Methodology for article selection. 
To be deemed appropriate for this review, the articles had to include at least one of the following widely recognized forms of early life stress: emotional abuse, sexual abuse, physical abuse, emotional neglect, and physical neglect. These categories were based on descriptions found in the major studies on this issue (Bernstein et al., 1994; Butchart, 2006; Grassi-Oliveira, Stein, \& Pezzi, 2006). Studies that only explored other forms of childhood adversity such as parental loss or separation, parental psychiatric disorders, or a wide range of early stressful life events were considered outside the scope of this review. The methodological scheme for the selection of articles is shown in detail in Figure 1.

\section{Results}

PubMed identified 208 articles, and SciELO identified 39 articles. The combined searches yielded a total of 247 articles. Following the application of the exclusion criteria, we selected 32 items, and one of these was excluded because it was a duplicate study between the databases, yielding a total of 31 articles to be examined in this review. See the main results of the articles in more detail in Table 1.

\section{Characterization studies}

The assessment of early life stress was not uniform, but most studies utilized an internationally recognized

Table 1. Description of main results of selected articles

\begin{tabular}{|c|c|c|c|}
\hline Author/Year & $\begin{array}{l}\text { Subtype of early life } \\
\text { stress }\end{array}$ & Diagnosis & Main results \\
\hline McLaughlin et al., 2010 & $\mathrm{SA}, \mathrm{PA}, \mathrm{N}$ & $\mathrm{MD}, \mathrm{AD}, \mathrm{SAD}, \mathrm{PD}$ & $\begin{array}{l}\text { Neglect and physical and sexual abuse } \\
\text { were associated with anxiety and mood } \\
\text { disorders. }\end{array}$ \\
\hline Green et al., 2010 & $\mathrm{SA}, \mathrm{PA}, \mathrm{N}$ & $\mathrm{MD}, \mathrm{AD}, \mathrm{SAD}, \mathrm{PD}$ & $\begin{array}{l}\text { Neglect and sexual and physical abuse } \\
\text { were strongly associated with the onset } \\
\text { of psychiatric disorders in childhood and } \\
\text { adulthood. }\end{array}$ \\
\hline Rubino et al., 2009 & SA, PA, EA & $\mathrm{S}, \mathrm{MD}$ & $\begin{array}{l}\text { Physical and emotional abuse were asso- } \\
\text { ciated with schizophrenia. }\end{array}$ \\
\hline $\begin{array}{l}\text { Medley \& Sachs-Ericsson, } \\
2009\end{array}$ & SA, PA & $\mathrm{MD}, \mathrm{AD}, \mathrm{SAD}, \mathrm{PD}$ & $\begin{array}{l}\text { Victims of sexual abuse were more likely } \\
\text { to display abusive behavior toward their } \\
\text { children. }\end{array}$ \\
\hline Afifi et al., 2009 & $\mathrm{SA}, \mathrm{PA}, \mathrm{N}$ & $\mathrm{MD}, \mathrm{AD}, \mathrm{SAD}, \mathrm{PD}$ & $\begin{array}{l}\text { Exposure to neglect and physical and } \\
\text { sexual abuse triggered posttraumatic } \\
\text { stress disorder, conduct disorder, and } \\
\text { suicide attempts. }\end{array}$ \\
\hline Sfoggia et al., 2008 & SA, PA, EA, EN, PN & $\mathrm{MD}, \mathrm{AD}, \mathrm{SAD}, \mathrm{PD}$ & $\begin{array}{l}\text { Severe abuse or neglect were associated } \\
\text { with a higher propensity for suicidal } \\
\text { behaviors. }\end{array}$ \\
\hline Caspi et al., 2008 & SA & $\mathrm{MD}, \mathrm{AD}, \mathrm{PD}$ & $\begin{array}{l}\text { Sexual abuse associated with physi- } \\
\text { cal abuse was found in patients with } \\
\text { obsessive-compulsive disorder and panic } \\
\text { disorder. }\end{array}$ \\
\hline Afifi et al., 2008 & SA, PA & $\mathrm{MD}, \mathrm{AD}, \mathrm{SAD}$ & $\begin{array}{l}\text { Physical and sexual abuse was associated } \\
\text { with the development of psychiatric dis- } \\
\text { orders and suicidal tendencies. }\end{array}$ \\
\hline Afifi et al., 2007 & SA, PA, EA, EN & $\mathrm{MD}, \mathrm{AD}, \mathrm{SAD}, \mathrm{S}$ & $\begin{array}{l}\text { Psychiatric symptoms were more intense } \\
\text { in individuals who suffered neglect and } \\
\text { sexual, physical, and emotional abuse. }\end{array}$ \\
\hline Wonderlich et al., 2007 & SA, PA, EA, PN & $\mathrm{PD}, \mathrm{AD}, \mathrm{MD}, \mathrm{SAD}$ & $\begin{array}{l}\text { Sexual abuse was associated with anxiety } \\
\text { and mood disorders, and emotional abuse } \\
\text { was associated with eating disorders. }\end{array}$ \\
\hline
\end{tabular}


Table 1. Continued

\begin{tabular}{ll}
\hline Author / Year & $\begin{array}{l}\text { Subtype of early life Diagnosis } \\
\text { stress }\end{array}$ \\
\hline
\end{tabular}

Grover et al., 2007

Zavaschi et al., 2006

Afifi et al., 2006

Sachs-Ericsson, Blazer,

Plant, \& Arnow, 2005

Bandelow et al., 2005

Bebbington et al., 2004

Sar et al., 2004

Holowka et al., 2003

Roy, 2002

Lewis-Fernández et al., 2002

Molnar et al., 2001

Johnson et al., 2001

Bulik, Prescott, \& Kendler, 2001
SA, PA, EA, EN, PN PD

SA, PA, EA, EN, PN MD

PA

SA, PA

SA

$\mathrm{AD}, \mathrm{PD}$

SA

S

$\mathrm{SA}, \mathrm{PA}, \mathrm{EA}, \mathrm{EN}, \mathrm{PN}$ DD

SA, PA, EA, EN, PN

S

SA, PA, EA, EN, PN AD, PD

PA

AD

SA

$\mathrm{MD}, \mathrm{AD}, \mathrm{SAD}$

SA, PA, N

AD, PD

SA

MD, AD, SAD
A history of early life stress was associated with reporting more symptoms of subclinical paranoia, narcissistic, borderline, antisocial, obsessive-compulsive, passive-aggressive, and depressive personality disorders.

Patients with mania had high rates of physical and sexual abuse.

Physical abuse was associated with the development of major depressive disorder and substance abuse.

Lifetime psychiatric problems partially mediated the relationship between abuse and health.

A high incidence of childhood sexual abuse was found in patients with borderline personality disorder.

The prevalence of sexual abuse was higher in patients at risk for psychosis.

Neglect and physical and emotional abuse were found in patients with conversion disorder and dissociative disorder.

Emotional abuse played an important role in the etiology of dissociation schizophrenia.

A positive association was found between Childhood Trauma Questionnaire scores and the scales of severity of psychiatric symptoms in patients who suffered emotional, physical, and sexual abuse and emotional and physical neglect.

Physical abuse was not associated with ataque frequency.

The severity of sexual abuse was associated with the development of more serious psychiatric disorders.

Victims of emotional abuse were three-fold more likely to have borderline, narcissistic, obsessive-compulsive, and paranoid personality disorders. Physical and emotional abuse could lead to personality disorder.

Child sexual abuse was associated with psychiatric disorders in the future. 
Table 1. Continued

\begin{tabular}{|c|c|c|c|}
\hline Author / Year & $\begin{array}{l}\text { Subtype of early life } \\
\text { stress }\end{array}$ & Diagnosis & Main results \\
\hline Brown et al., 1999 & SA, PA, N & MD & $\begin{array}{l}\text { Individuals who experienced early life } \\
\text { stress were more likely to experience de- } \\
\text { pression and attempted suicide. Sexual } \\
\text { abuse increased the likelihood of commit- } \\
\text { ting suicide eight-fold. }\end{array}$ \\
\hline Johnson et al., 1999 & SA, PA, EN, PN & PD & $\begin{array}{l}\text { Victims of neglect and sexual and physical } \\
\text { abuse were four-fold more likely to develop } \\
\text { personality disorder compared with those } \\
\text { who were not abused. }\end{array}$ \\
\hline Giese et al., 1998 & SA, PA & MD & $\begin{array}{l}\text { Childhood abuse may be associated with an } \\
\text { earlier onset of affective episodes. }\end{array}$ \\
\hline Welch \& Fairburn, 1996 & SA, PA & ED & $\begin{array}{l}\text { Sexual and physical abuse was a risk fac- } \\
\text { tors for psychiatric disorders, but bulimia } \\
\text { nervosa was associated with recurring } \\
\text { sexual abuse. }\end{array}$ \\
\hline Folsom et al., 1993 & SA, PA & ED & $\begin{array}{l}\text { A negative association was found between } \\
\text { physical and sexual abuse and eating disor- } \\
\text { ders, but the nature of phobic and obsessive } \\
\text { psychiatric disorders was severe. }\end{array}$ \\
\hline Waller, 1993 & SA & $\mathrm{ED}, \mathrm{PD}$ & $\begin{array}{l}\text { An association was found between sexual } \\
\text { abuse and borderline personality disorder } \\
\text { and the presence of eating disorders, espe- } \\
\text { cially bulemia. }\end{array}$ \\
\hline Pribor \& Dinwiddie, 1992 & SA & $\begin{array}{l}\mathrm{MD}, \mathrm{AD}, \mathrm{SAD} \\
\mathrm{PD}, \mathrm{S}\end{array}$ & $\begin{array}{l}\text { Sexual abuse-related anxiety disorders, } \\
\text { depression, and alcohol dependence were } \\
\text { found. }\end{array}$ \\
\hline
\end{tabular}

SA, sexual abuse; EA, emotional abuse; PA, physical abuse; N, neglect; PN, physical neglect; EN, emotional neglect; MD, mood disorder; AD, anxiety disorder; SAD, substance abuse disorders; PD, personality disorder; S, schizophrenia and psychotic disorders; DD, dissociative disorders; ED, eating disorder. variables in the selected articles.

interview. Among the studies, the most consistently employed measure was the Childhood Trauma Questionnaire, which was used in six studies, followed by the Conflict Tactics Scale, which was used in four studies. Other instruments used were the following: Abuse Questionnaire, Screening Survey of Children's

Subtypes of Early Life Stress

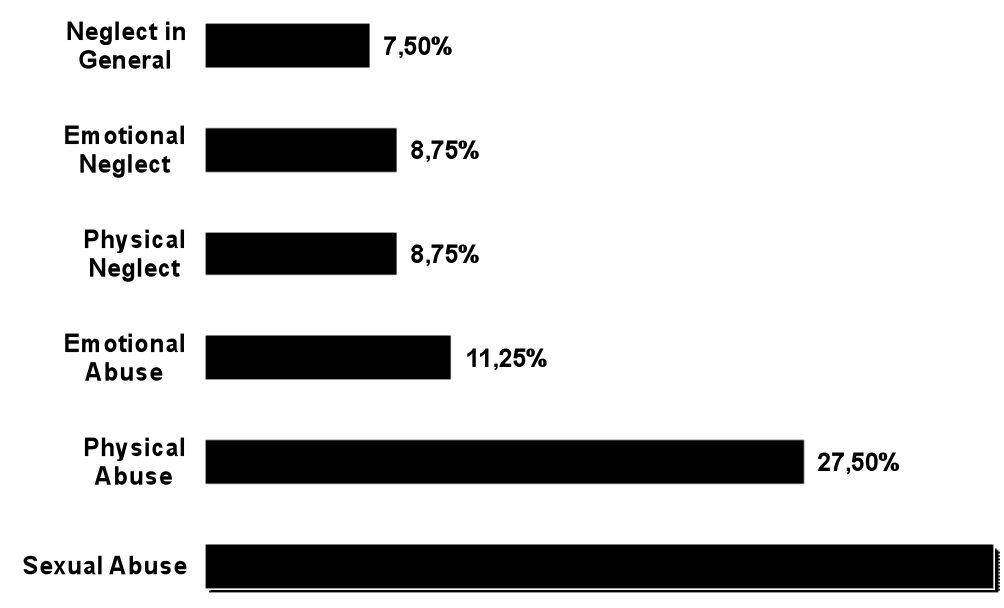

$36,25 \%$

Figure 2. Distribution of subtypes of early life stress in the articles selected for this review. 
Exposure to Community Violence, Self-Report Sexual Life, Traumatic Antecedents Questionnaire, Childhood Trauma Interview, as well as various Interview Retrospectives, registration Bulletins Occurrence and Section of PTSD (posttraumatic stress disorder) ICD-10.

The sample sizes ranged from 26 patients to 8,580 patients, thus making the comparability of the findings difficult. The gender composition of the samples also varied. Although most articles (25) assessed the prevalence of early life stress in men and women, six articles assessed only women. Furthermore, the age criteria for inclusion in the studies ranged from 15 to 74 years. The sample was not homogeneous in the control group. Of the 31 articles, 17 used a control group, and 14 did not. Additionally, some studies used subjects without psychiatric disorders as a control group, whereas other studies used only subjects without early life stress as a control. The vast majority of studies were published in English in high-impact journals, and only three studies were published in Portuguese.

The distribution of early stress subtypes in the selected articles showed that the following types of abuse were the most often studied: sexual abuse $(36.25 \%)$, physical abuse $(27.5 \%)$, and emotional abuse $(11.25 \%)$, followed by a lower percentage of neglect, as shown in Figure 2. Only six of the 31 prevalence studies assessed all five major forms of early life stress, and thus the vast majority were not able to control for overlapping experiences or determine the independent effects of each type of abuse and neglect.

The selected articles were also not evenly distributed with regard to the assessment of psychiatric disorders associated with early life stress. Most studies assessed the association between early life stress with anxiety disorders $(67.7 \%)$, followed by mood disorders (61.29\%), substance abuse disorders, and personality disorders, both of which were evaluated by the same percentage of studies (48.38\%). For more details, see Figure 3.

\section{Main results}

This review describes the occurrence of early life stress and its association with psychiatric disorders. A positive association was found between early life stress and the development of psychopathology in adulthood in approximately $94 \%$ of the articles. This positive association was identified in the study conducted by Pribor and Dinwiddie (1992) in which the authors found high rates of psychiatric disorders in the sample, especially anxiety disorders (e.g., agoraphobia, panic disorder, posttraumatic stress disorder, social phobia, and simple phobia) followed by depression and alcohol dependence in sexually abused individuals, unlike the control group. In a recent study, Wonderlich et al. (2007) reported similar findings, associating sexual abuse with the development of anxiety disorders and mood disorders in adulthood. However, Afifi, Brownridge, Cox, and Sareen (2006) and Zavaschi et al. (2006) found an association between adult mood disorders and physical abuse in childhood. Afifi et al. (2006) found a higher chance of developing major depression, followed by alcohol dependence or abuse and externalizing problems in individuals who suffered physical abuse. Zavaschi et al. (2006) found an increase in this association, especially in manic patients.

Although the studies assessed in this systematic review showed controversial evidence regarding the subtype of early life stress associated with anxiety

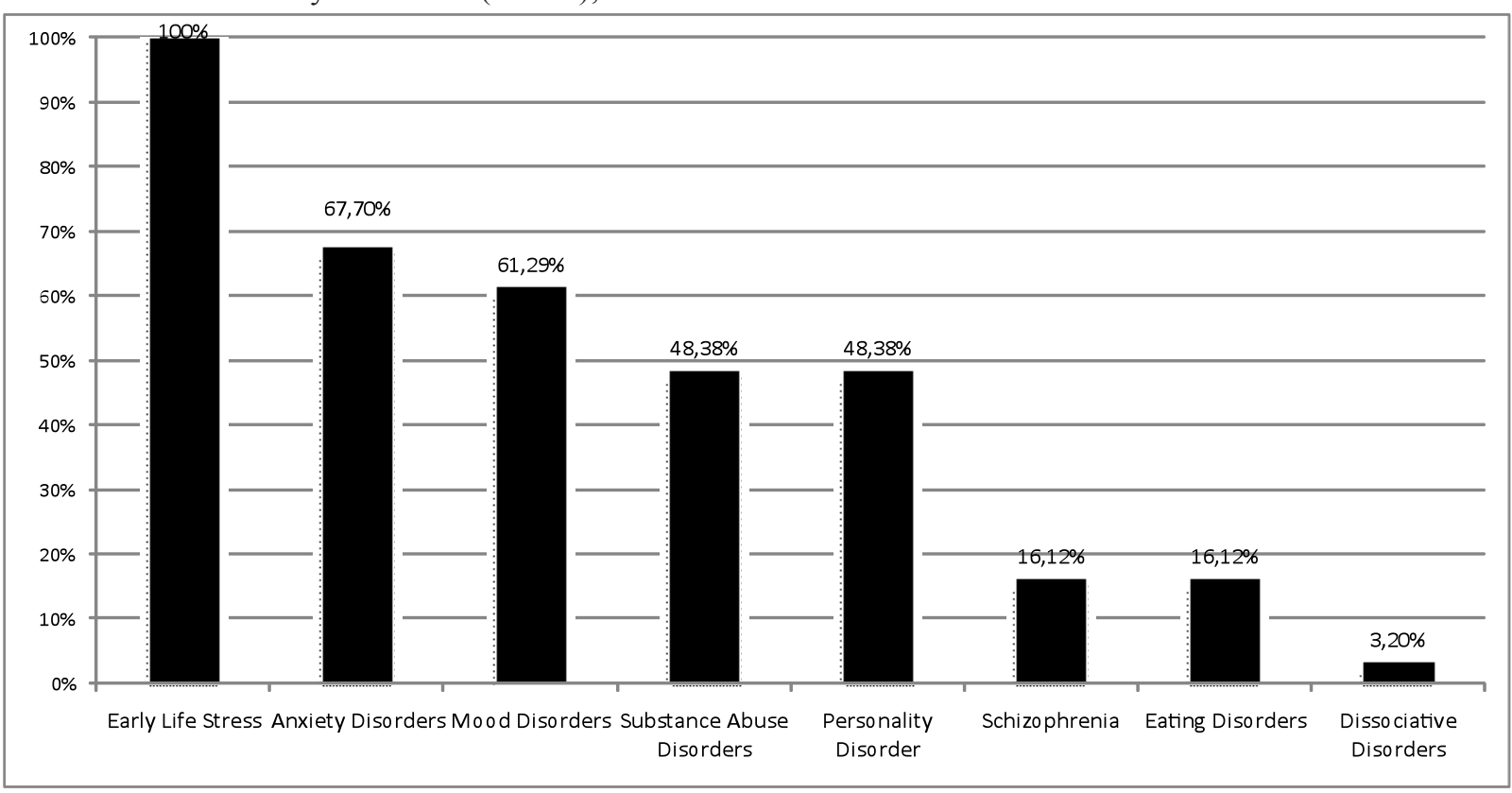

Figure 3. Distribution of variables in the selected articles. 
disorders and mood disorders, Holowka, King, Saheb, Pukall, and Brunet (2003) and Rubino, Nanni, Pozzi, and Siracusano (2009) demonstrated consistent findings about the important role of emotional abuse in the etiology of schizophrenia.

With regard to dissociative disorders, only one article was found in this review. In the study conducted by Sar, Akyüz, Kundakçi, Kiziltan, and Dogan (2004), patients with dissociative disorder reported physical neglect and emotional and sexual abuse more frequently. The quantitative measures demonstrated that they had significantly high scores for all types of abuse and neglect and high total childhood trauma scores, whereas patients with conversion disorder without dissociative disorder were more prone to minimize their trauma history.

The present review also identified important articles that associated greater exposure to early life stress with an increase in suicidal ideation and suicide attempts (Afifi et al., 2008; Afifi, Boman, Fleisher, \& Sareen, 2009). According to Brown, Cohen, Johnson, and Smailes (1999), victims of neglect and physical abuse were three-fold more prone to depression and suicide than those who were not abused. Furthermore, the occurrence of sexual abuse increased the likelihood of committing suicide eight-fold.

Most of the papers suggested that different types of early life stress are associated with personality disorders in adulthood. One of the most consistent findings in this review was the association between borderline personality disorder and sexual abuse (Bandelow et al., 2005; Grover et al., 2007; Johnson, Cohen, Brown, Smailes, \& Bernstein, 1999; Johnson et al., 2001; Waller, 1993). However, Johnson et al. (1999, 2001) suggested that verbal abuse during childhood may contribute to the development of some types of personality disorders such as borderline, narcissistic, paranoid, schizoid, and schizotypal, independent of offspring temperament, physical abuse, sexual abuse, neglect, physical punishment during childhood, parental education, parental psychopathology, and the co-occurrence of psychiatric disorders.

Some articles included in this review provided additional data that are relevant to understanding the mechanisms involved in the association between early life stress and psychopathology in adulthood. McLaughlin et al. (2010) asserted that not only the amount of early life stress that the subject has suffered but also its nature determines the early onset of psychopathology. Moreover, when comparing people who suffered and people who did not suffer early life stress, the severity score of psychiatric symptoms was higher in abused individuals (Afifi et al., 2007). Giese, Thomas, Dubovsky, and Hilty (1998) suggested that a history of childhood abuse may be associated with earlier and perhaps more frequent hospital admissions for affective disorders and more frequent comorbid personality disorders.
Regarding the controversial data, only two articles selected in this review did not show an association between early life stress and psychiatric disorders. However, the results of these two articles should be assessed cautiously. The study by Lewis-Fernández et al. (2002), in addition to evaluating a very small sample of women, presented a limitation in design that only allows the conclusion that early life stress was not associated with ataque frequency. In the study by Folsom et al. (1993), however, although the authors found no correlation between a history of sexual abuse and the severity of eating disorder symptoms, they found more severe psychiatric disorders of an obsessive and phobic nature in the group of abused subjects than in non-abused subjects. Thus, the findings in these articles appear to be insufficient to negate the association between early life stress and psychiatric disorders because most studies found positive associations.

\section{Discussion}

Most of the articles assessed in this review found a positive association between early life stress and the development of future psychopathology. However, these findings must be evaluated carefully because these studies have limitations. One of the primary limitations concerns the fact that no consensus was found in the literature on the concept of early life stress. Thus, although the most widely used instrument in the articles included in this review was the Childhood Trauma Questionnaire, which assesses five subtypes of trauma (physical, emotional, and sexual abuse and physical and emotional neglect), several other studies evaluated other subtypes of early life stress such as parental loss, family psychiatric disorders, family violence, and economic hardship. The difficulty in collecting these data should also be considered because interviewees in these studies were likely to underestimate the frequency/intensity of the events, so the data may be subject to bias, thus affecting their reliability. However, some patients, such as borderline patients, may confabulate abuse histories or exaggerate certain events. Splitting (i.e., perceiving others as all good or all bad) may make a borderline patient more likely to see the family as malignant or abusive (Herman, Perry, \& van der Kolk, 1989; Bandelow et al., 2005).

Moreover, other limitations to assessing the relative impact of early life stress on later psychopathology is embedded in the issue of the multiplicity of the forms of maltreatment that occurs over time. Predicting the developmental period in which an abused or neglected child may be at greater risk of developing later psychopathology may not depend solely on when the abuse occurred. Complicating factors include the different types of maltreatment that occur simultaneously or in succession over the 
developmental span. Notably, neglect was little studied in the articles discussed in this review as a risk factor for the development of psychopathology because it appears to be associated with other subtypes. Not investigating the independent potential of negligence affecting the onset of psychiatric disorders in adults is a limitation of this area.

Assessing the timing of the occurrence of maltreatment in relation to the emergence of psychopathology is also particularly difficult. Data on the timing of child maltreatment are scarce and potentially unreliable. Of the studies evaluated in this review, the majority had a retrospective crosssectional design, which greatly undermines the reliability of the data because this information depends on the respondent's recollection of past events. Thus, longitudinal studies that collect data on maltreatment prospectively and over different developmental stages would permit the evaluation of the different types of maltreatment that occur simultaneously.

Another limitation found in this review is the paucity of research that investigated the level of severity, frequency, and recurrence of early life stress. The studies are still deficient with regard to the investigation of psychiatric comorbidity and the profiles of the victim and abuser. This is extremely important information when seeking to broaden the knowledge about the complex interactions that involve the association between early life stress and psychopathology in adulthood.

Despite the several limitations of the articles discussed in this review, relevant findings regarding the association between severity of early life stress and the onset of suicide attempts in psychiatric patients (Molnar, Berkman, \& Buka, 2001; Molnar, Buka, \& Kessler, 2001; Green et al., 2010; Sfoggia, Pacheco, \& Grassi-Oliveira, 2008) reveal a public health problem. Furthermore, the traumatic events experienced in childhood become risk factors for sexual, physical, and emotional victimization in adulthood, especially by intimate partners, consolidating the intergenerational character of violence and indicating that victims of different subtypes of early stress are almost twice as likely to exhibit abusive behavior toward children for conflict resolution compared with those who reported no childhood abuse (Medley \& Sachs-Ericsson, 2009). Thus, further studies are needed in this area to clarify the mechanisms by which early life stress is a risk factor for triggering future psychopathology.

\section{Conclusions}

Exposure to many adversities during childhood and adolescence is predictive of psychiatric disorders in adulthood. Most studies indicate positive associations that provide scientific evidence on this relationship. The results of existing studies demonstrate the importance of such understanding among professionals concerned with the issue of early life stress and preventive practices aimed at the mechanisms involved in the process of victimization.

\section{References}

Abramovitch, S., Maia, M.C., \& Cheniaux, E. (2008). Attentiondeficit and disruptive behavior disorders: association with physical abuse in childhood. Revista de Psiquiatria Clinica, 35, 159-164.

Aded, N.L.O., Dalcin, B.L.G.S., Moraes, T.M., \& Cavalcanti, M.T. (2006). Abuso sexual em crianças e adolescentes: revisão de 100 anos de literatura. Revista de Psiquiatria Clínica, 33, 204-213.

Afifi, T.O., Boman, J., Fleisher, W., \& Sareen, J. (2009). The relationship between child abuse, parental divorce, and lifetime mental disorders and suicidality in a nationally representative adult sample. Child Abuse and Neglect, 33, 139-147.

Afifi, T.O., Brownridge, D.A., Cox, B.J., \& Sareen, J. (2006). Physical punishment, childhood abuse and psychiatric disorders. Journal of Child Abuse and Neglect, 30, 1093-1103.

Afifi, T.O., Enns, M.W., Cox, B.J., Asmundson, G.J., Stein, M.B., \& Sareen, J. (2008). Population attributable fractions of psychiatric disorders and suicide ideation and attempts associated with adverse childhood experiences. American Journal of Public Health, 98, 946-952.

Afifi, T.O., Enns, M.W., Cox, B.J., de Graaf, R., ten Have, M., \& Sareen, J. (2007). Child abuse and health-related quality of life in adulthood. Journal of Nervous and Mental Disease, 195, 797-804.

Anda, R.F., Felitti, V.J., Bremner, J.D., Walker, J.D., Whitfield, C., Perry, B.D., Dube, S.R., \& Giles, W.H. (2006). The enduring effects of abuse and related adverse experiences in childhood: a convergence of evidence from neurobiology and epidemiology. European Archives of Psychiatry and Clinical Neuroscience, 256, 174-186.

Bandelow, B., Krause, J., Wedekind, D., Broocks, A., Hajak, G., \& Rüther, E. (2005). Early traumatic life events, parental attitudes, family history, and birth risk factors in patients with borderline personality disorder and healthy controls. Psychiatry Research, 134, 169-179.

Barnett, D. (1997). The effects of early intervention on maltreating parents and their children. In: M.J. Guralnick (Ed.), The effectiveness of early intervention (pp. 143-173). Baltimore: P.H. Brookes.

Bebbington, P.E., Bhugra, D., Brugha, T., Singleton, N., Farrell, M., Jenkins, R., Lewis, G., \& Meltzer, H. (2004). Psychosis, victimisation and childhood disadvantage: evidence from the second British National Survey of Psychiatric Morbidity. British Journal of Psychiatry, 185, 220-226.

Bernstein, D.P., Fink, L., Handelsman, L., Foote, J., Lovejoy, M., Wenzel, K., Sapareto, E., \& Ruggiero, J. (1994). Initial reliability and validity of a new retrospective measure of child abuse and neglect. American Journal of Psychiatry, 151, 1132-1136.

Brancalhone, P.G., Fogo, J.C., \& Williams, L.C.A. (2004). Crianças expostas à violência conjugal: avaliação do desempenho acadêmico. Psicologia: Teoria e Pesquisa, 20, 113-117.

Bremne, J.D., \& Vermetten, E. (2001). Stress and development: behavioral and biological consequences. Developmental Psychopathology, 13, 473-489.

Brewerton, T.D. (2007). Eating disorders, trauma, and comorbidity: focus on PTSD. Eating Disorders, 15, 285-304.

Brown, J., Cohen, P., Johnson, J.G., \& Smailes, E.M. (1999). Childhood abuse and neglect: specificity of effects on adolescent and young adult depression and suicidality. Journal of the American Academy of Child and Adolescent Psychiatry, 38, 1490-1496.

Bulik, C.M., Prescott, C.A., \& Kendler, K.S. (2001). Features of childhood sexual abuse and the development of psychiatric and substance use disorders. British Journal of Psychiatry, 179, 444-449.

Butchart, A. (2006). Preventing child maltreatment: a guide to taking action and generating evidence. Geneva: World Health Organization.

Cardoso, E.S., Santana, J.S.S., \& Ferriani, M.G.C. (2006). Criança e adolescente vítimas de Maus-Tratos: informações dos enfermeiros de um Hospital Público. Revista Enfermagem UERJ, 14, 524-530.

Caspi, A., Vishne, T., Sasson, Y., Gross, R., Livne, A., \& Zohar, J. (2008). Relationship between childhood sexual abuse and obsessive-compulsive disorder: case control study. Israel Journal of Psychiatry and Related Sciences, 45, 177-182.

Cruz, D.M.C., Silva, J.T., \& Alves, H.C. (2007). Evidências sobre 
violência e deficiência: implicações para futuras pesquisas. Revista Brasileira de Educação Especial, 13(1), 131-146.

Folsom, V., Krahn, D., Nairn, K., Gold, L., Demitrack, M.A., \& Silk, K.R. (1993). The impact of sexual and physical abuse on eating disordered and psychiatric symptoms: a comparison of eating disordered and psychiatric inpatients. International Journal of Eating Disorders, 13, 249-257.

Giese, A.A., Thomas, M.R., Dubovsky, S.L., \& Hilty, S. (1998). The impact of a history of childhood abuse on hospital outcome of affective episodes. Psychiatric Services, 49(1), 77-81.

Grassi-Oliveira, R., Stein, L.M., \& Pezzi, J.C. (2006). Traducão e validação de conteúdo da versão em português do Childhood Trauma Questionnaire. Revista de Saúde Pública, 40, 249-255.

Green, J.G., McLaughlin, K.A., Berglund, P.A., Gruber, M.J., Sampson, N.A., Zaslavsky, A.M., \& Kessler, R.C. (2010). Childhood adversities and adult psychiatric disorders in the National Comorbidity Survey Replication I: associations with first onset of DSM-IV disorders. Archives of General Psychiatry, 67, 113-123.

Grover, K.E., Carpenter, L.L., Price, L.H., Gagne, G.G., Mello, A.F., Mello, M.F., \& Tyrka, A.R. (2007). The relationship between childhood abuse and adult personality disorder symptoms. Journal of Personality Disorders, 21, 442-447.

Herman, J.L., Perry, J.C., \& van der Kolk, B.A. (1989). Childhood trauma in borderline personality disorder. American Journal of Psychiatry, 146, 490-495.

Holowka, D.W., King, S., Saheb, D., Pukall, M., \& Brunet, A. (2003). Childhood abuse and dissociative symptoms in adult schizophrenia. Schizophrenia Research, 60(1), 87-90.

Johnson, J.G., Cohen, P., Brown, J., Smailes, E.M., \& Bernstein, D.P. (1999). Childhood maltreatment increases risk for personality disorders during early adulthood. Archives of General Psychiatry, $56,600-606$.

Johnson, J.G., Cohen, P., Smailes, E.M., Skodol, A.E., Brown, J., \& Oldham, J.M. (2001). Childhood verbal abuse and risk for personality disorders during adolescence and early adulthood. Comprehensive Psychiatry, 42(1), 16-23.

Juruena, M.F. (2007). The neurobiology of treatment resistant depression: role of the hypothalmic-pituitary-adrenal axis and glucocorticoid and mineralocorticoid receptor function. ( $\mathrm{PhD}$ thesis), University of London, King's College London, Institute of Psychiatry.

Lewis-Fernández, R., Garrido-Castillo, P., Bennasar, M.C., Parrilla, E.M., Laria, A.J., Ma, G., \& Petkova, E. (2002). Dissociation, childhood trauma, and ataque de nervios among Puerto Rican psychiatric outpatients. American Journal of Psychiatry, 159, 1603-1605.

McLaughlin, K.A., Green, J.G., Gruber, M.J., Sampson, N.A., Zaslavsky, A.M., \& Kessler, R.C. (2010). Childhood adversities and adult psychiatric disorders in the National Comorbidity Survey Replication II: associations with persistence of DSM-IV disorders. Archives of General Psychiatry, 67, 124-132.

Medley, A., \& Sachs-Ericsson, N. (2009). Predictors of parental physical abuse: the contribution of internalizing and externalizing disorders and childhood experiences of abuse. Journal of Affective Disorders, 113, 244-254.

Mello, M.F., Faria, A.A., Mello, A.F., Carpenter, L.L., Tyrka, A.R., \& Price, L.H. (2009). Maus-tratos na infância e psicopatologia no adulto: caminhos para a disfunção do eixo hipotálamo-pituitária- adrenal. Revista Brasileira de Psiquiatria, 31(2), 41-48.

Mello, A.A., Mello, M.F., Carpenter, L.L., \& Price, L.H. (2003). Update on stress and depression: the role of the hypothalamic-pituitaryadrenal (HPA) axis. Revista Brasileira de Psiquiatria, 5, 231-238.

Molnar, B.E., Berkman, L.F., \& Buka, S.L. (2001). Psychopathology, childhood sexual abuse and other childhood adversities: relative links to subsequent suicidal behaviour in the US. Psychological Medicine, 31, 965-977.

Molnar, B.E., Buka, S.L., \& Kessler, R.C. (2001). Child sexual abuse and subsequent psychopathology: results from the National Comorbidity Survey. American Journal of Public Health, 91, 753-760.

Pribor, E.F., \& Dinwiddie, S.H. (1992). Psychiatric correlates of incest in childhood. American Journal of Psychiatry, 149(1), 52-56.

Rosenberg, S.D., Drake, R.E., \& Mueser, K. (1996). New directions for treatment research on sequelae of sexual abuse in persons with severe mental illness. Community Mental Health Journal, 32, 387-400.

Roy, A. (2002). Childhood trauma and neuroticism as an adult: possible implication for the development of the common psychiatric disorders and suicidal behaviour. Psychological Medicine, 32, 1471-1474.

Rubino, I.A., Nanni, R.C., Pozzi, D.M., \& Siracusano, A. (2009). Early adverse experiences in schizophrenia and unipolar depression. Journal of Nervous and Mental Disease, 197(1), 65-68.

Sachs-Ericsson, N., Blazer, D., Plant, E.A., \& Arnow, B. (2005). Childhood sexual and physical abuse and the 1-year prevalence of medical problems in the National Comorbidity Survey. Health Psychology, 24(1), 32-40.

Sar, V., Akyüz, G., Kundakçi, T., Kiziltan, E., \& Dogan, O. (2004). Childhood trauma, dissociation, and psychiatric comorbidity in patients with conversion disorder. American Journal of Psychiatry, 161, 2271-2276.

Sfoggia, A., Pacheco, M.A., \& Grassi-Oliveira, R. (2008). History of childhood abuse and neglect and suicidal behavior at hospital admission. Journal of Crisis Intervention, 29, 154-158.

Waller, G. (1993). Association of sexual abuse and borderline personality disorder in eating disordered women. International Journal of Eating Disorders, 13, 259-263.

Webster-Stratton, C. (1997). Early intervention for families of pre-school children with conduct problems. In: M.J. Guralnick (Ed.), The effectiveness of early intervention (pp. 429-453). Baltimore: P.H. Brookes.

Welch, S.L., \& Fairburn, C.G. (1996). Childhood sexual and physical abuse as risk factors for the development of bulimia nervosa: a communitybased case control study. Child Abuse and Neglect, 20, 633-642.

Wonderlich, S.A., Rosenfeldt, S., Crosby, R.D., Mitchell, J.E., Engel, S.G., Smyth, J., \& Miltenberger, R. (2007). The effects of childhood trauma on daily mood lability and comorbid psychopathology in bulimia nervosa. Journal of Traumatic Stress, 20(1), 77-87.

Zavaschi, M.L.S., Graeff, M.E., Menegassi, M.T., Mardini, V., Pires, D.W.S., Carvalho, R.H., Rohde, L.A., \& Eizirik, C.L. (2006) Adult mood disorders and childhood psychological trauma. Revista Brasileira de Psiquiatria, 28, 184-190.

Zavaschi, M.L.S., Satler, F., Poester, D., Vargas, C.F., Piazenski, R., Rohde, L.A.P., \& Eizirik, C.L. (2002). Associação entre trauma por perda na infância e depressão na vida adulta. Revista Brasileira de Psiquiatria, 24, 189-195. 